\title{
Colonoscopic Polypectomy Preferences of Asian Endoscopists: Results of a Survey-Based Study
}

\author{
Dong-Hoon Yang ${ }^{1}$, Bayasgalan Luvsandagva 2,3 , Quang Trung Tran ${ }^{4,5}$, Achmad Fauzi $^{6}$, Panida Piyachaturawat ${ }^{7}$, \\ Thida Soe ${ }^{8}$, Zhiqin Wong ${ }^{9}$, and Jeong-Sik Byeon ${ }^{1}$ \\ ${ }^{1}$ Department of Gastroenterology, Asan Medical Center, University of Ulsan College of Medicine, Seoul, Korea, ${ }^{2}$ Department of \\ Endoscopy, Ulaanbaatar Songdo Hospital, Ulaanbaatar, Mongolia, ${ }^{3}$ Division of Gastroenterology, Union Hospital, Tongji Medical \\ College, Huazhong University of Science and Technology, Wuhan, China, ${ }^{4}$ Department of Internal Medicine, University of Medicine \\ and Pharmacy, Hue University, Hue, Vietnam, ${ }^{5}$ Department of Medicine A, University Medicine Greifswald, Greifswald, Germany, \\ ${ }^{6}$ Division of Gastroenterology, Department of Internal Medicine, Dr. Cipto Mangunkusumo National General Hospital, Jakarta, \\ Indonesia, ${ }^{7}$ Division of Gastroenterology, Department of Medicine, King Chulalongkorn Memorial Hospital, Faculty of Medicine, \\ Chulalongkorn University, Bangkok, Thailand, ${ }^{8}$ Department of Gastroenterology, University of Medicine 1 Yangon, Yangon, Myanmar, \\ and ${ }^{9}$ Gastroentorology Unit, Department of Medicine, Faculty of Medicine, National University of Malaysia, Kuala Lumpur, Malaysia
}

\section{Article Info}

Received May 2, 2020

Revised June 14, 2020

Accepted June 26, 2020

Published online August 26, 2020

\section{Corresponding Author}

Jeong-Sik Byeon

ORCID https://orcid.org/0000-0002-9793-6379

E-mail jsbyeon@amc.seoul.kr

Dong-Hoon Yang and Bayasgalan Luvsandagva contributed equally to this work as first authors.
Background/Aims: The clinical practice pattern of polypectomy is not well-investigated in Asian countries. We aimed to survey Asian endoscopists about their preferred polypectomy techniques for given conditions and images of polyps.

Methods: A survey was performed using questionnaires composed of two parts: a scenariobased questionnaire using scenarios of polyps, which were adopted from the European Society of Gastrointestinal Endoscopy guidelines, and an image-based questionnaire using provided endoscopic images of polyps.

Results: A total of 154 endoscopists participated in this survey. The most preferred resection techniques for diminutive $(\leq 5 \mathrm{~mm})$, small $(6-9 \mathrm{~mm})$, and benign-looking intermediate $(10-19 \mathrm{~mm})$ nonpedunculated polyps were cold forceps polypectomy, hot snare polypectomy, and endoscopic mucosal resection (EMR), respectively, in both the scenario- and image-based questionnaires. For benign-looking large ( $\geq 20 \mathrm{~mm}$ ) nonpedunculated polyps, EMR and endoscopic submucosal dissection (ESD) were preferred in the scenario- and image-based surveys, respectively. In case of malignant nonpedunculated polyps, EMR and ESD were preferred for intermediate-sized and large lesions, respectively, according to the scenario-based survey. However, ESD was preferred in both intermediate-sized and large malignant nonpedunculated polyps according to the imagebased survey. Trainee endoscopists, endoscopists working in referral centers, and endoscopists in the colorectal cancer-prevalent countries were independently associated with preference of cold snare polypectomy for removing small polyps.

Conclusions: The polypectomy practice patterns of Asian endoscopists vary, and cold snare polypectomy was not the most preferred resection method for polyps $<10 \mathrm{~mm}$ in size, in contrast to recent guidelines. (Gut Liver 2021;15:391-400)

Key Words: Colon; Rectum; Polyp; Polypectomy; Survey

\section{INTRODUCTION}

Colonoscopic polypectomy is one of the most important clinical interventions for preventing colorectal cancer (CRC) and reducing CRC-related mortality. ${ }^{1}$ Various types of techniques, including cold forceps polypectomy (CFP), hot forceps polypectomy, cold snare polypectomy (CSP), hot snare polypectomy (HSP), endoscopic mucosal dissection (EMR), endoscopic piecemeal mucosal resection (EPMR), and endoscopic submucosal dissection (ESD), have been introduced, ${ }^{2}$ and the technique is generally selected by endoscopists based on the size, morphology, and 
anticipated histology of the polyps.

Previously, surveys pertaining to endoscopists' preference of polypectomy methods have been performed in countries with high incidence of CRC. For example, CSP was the most preferred technique (31.2\%) for polyps 4 to 6 $\mathrm{mm}$ in size among U.S. endoscopists who participated in a survey in $2004 .{ }^{3}$ Meanwhile, $81.3 \%$ of Korean endoscopists chose CFP for polyps $\leq 5 \mathrm{~mm}$, and only $1.6 \%$ selected CSP for the same size of polyps in a survey published in $2011{ }^{4}$ According to survey-based studies published in 2014, Japanese endoscopists preferred CFP rather than CSP for polyps $\leq 5 \mathrm{~mm},{ }^{5}$ but Australian endoscopists preferred CSP for removing polyps smaller than or approximately $5 \mathrm{~mm} .{ }^{6}$ Lack of guidelines regarding the best optimal techniques for polypectomy may have led to such variability in selecting resection methods in earlier studies. In addition, owing to the different levels of attention given to the effectivity of CSP in en bloc resection of small polyps in each country, the preference for CSP might have varied in the contemporary surveys from Korea, Japan, and Australia. Subsequently, the European Society of Gastrointestinal Endoscopy (ESGE) published guidelines for colonoscopic polypectomy and EMR, ${ }^{6}$ which described the selection of resection methods based on polyp size, morphology, and histology. Recently, the U.S. Multi-Society Task Force on CRC also suggested endoscopic resection methods according to lesion size, morphology, and histology, ${ }^{7}$ comparable to the ESGE guidelines. Among the recommendations related to lesion resection, only CSP for polyps $<10 \mathrm{~mm}$ in size was based on the high-quality of evidence in both guidelines. ${ }^{2,7}$
According to data released from the International Agency for Research on Cancer, ${ }^{8}$ Asia contributes to more than half of the incidence and mortality cases of CRC in the world. However, wide ranges of variations in CRC incidence and CRC-related mortality rate were observed in Asian countries. ${ }^{8}$ The clinical practice of polypectomy for CRC prevention may also vary widely in Asia, but investigations on the subject are scant. Here, we surveyed gastrointestinal endoscopists from seven Asian countries to determine their preference regarding polypectomy techniques in their daily practices.

\section{MATERIALS AND METHODS}

\section{Study design}

A standardized online survey was conducted using a web-based survey system, SurveyMonkey (SurveyMonkey, San Mateo, CA, USA). The survey contained two parts. The first part included questions about the respondent's demographic information and experience as an endoscopist, and the questionnaire for the preferred polypectomy method (i.e., CFP, CSP, HSP, EMR [HSP after saline injection], EPMR, ESD, etc.) based on the given size, morphology, and estimated histology of polyps (scenario-based questionnaire) (Supplementary Table 1). The suggested polyp characteristics were adopted from the ESGE guidelines. ${ }^{2}$ The second part of the questionnaire provided 50 sets of endoscopic photos of polyps (Fig. 1), and two common questions were asked for each set of photos (image-
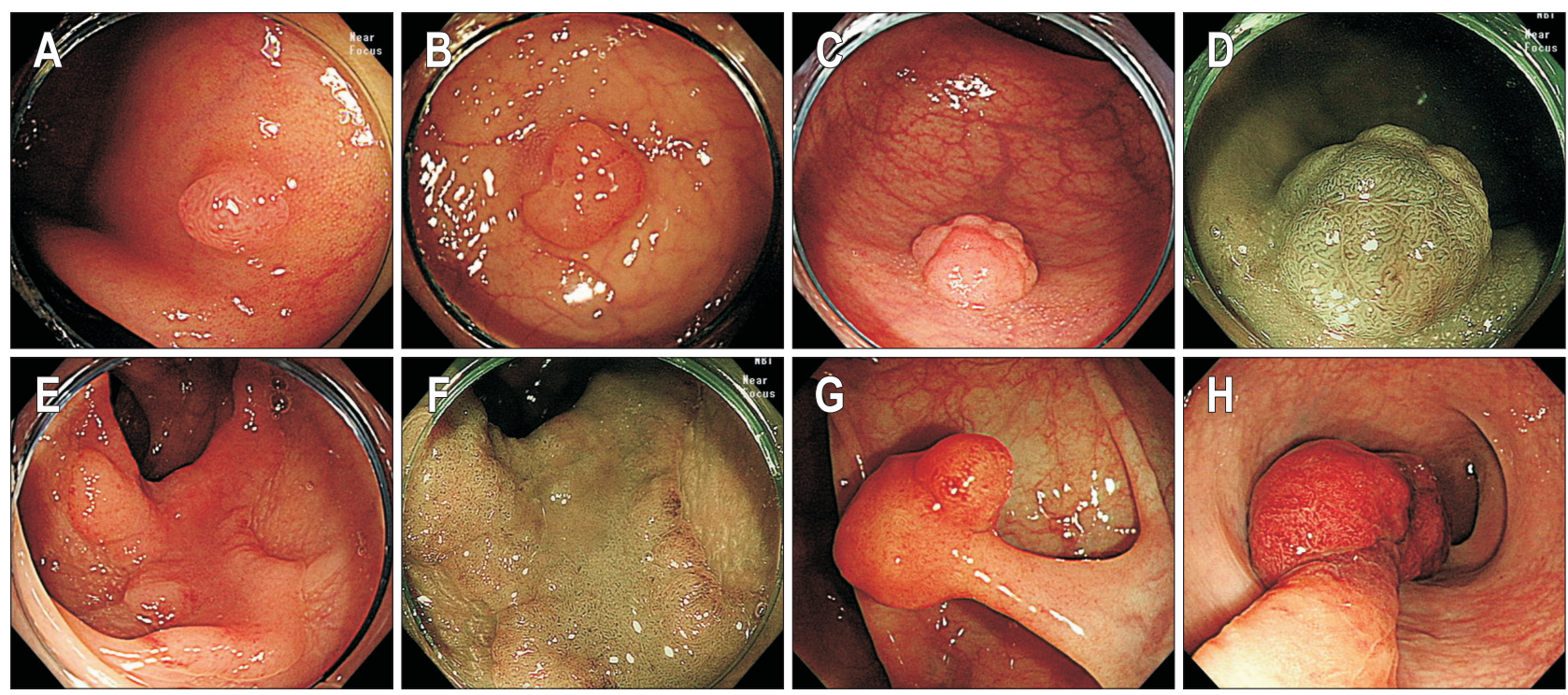

Fig. 1. Representative endoscopic images of polyps included in the image-based questionnaire. (A) A sessile polyp $\leq 5 \mathrm{~mm}$ (white light endoscopy, WLE), (B) a sessile polyp 6-9 $\mathrm{mm}$ in size (WLE), (C) a sessile polyp 10-19 $\mathrm{mm}$ in size (WLE), (D) a sessile polyp 10-19 $\mathrm{mm}$ in size (narrow-band image, NBI), (E) a flat polyp $\geq 20 \mathrm{~mm}$ (WLE), (F) a flat polyp $\geq 20 \mathrm{~mm}$ (NBI), (G) a pedunculated polyp with stalk width $<10 \mathrm{~mm}$ (WLE), (H) a pedunculated polyp with stalk width $\geq 10 \mathrm{~mm}$ (WLE). 
based questionnaire): (1) "Do you think this polyp may have submucosal invasive cancer?" and (2) "What is your preferred endoscopic resection method for this polyp?" A third question was asked for pedunculated polyps only, "Will you perform prophylactic hemostasis before endoscopic resection of this polyp?" (Supplementary Table 2). The age-standardized rate of CRC incidence and the rank of CRC incidence among all types of malignancies in each country were retrieved from the open-access database provided by the International Agency for Research on Cancer. ${ }^{8}$ This study was approved by the Institutional Review Board of Asan Medical Center (IRB number: 2018-0732). An expert endoscopist (J.S.B.) developed the initial version of the questionnaires. The final version of questionnaires was made after external review by six independent expert endoscopists (B.L., Q.T.T., A.F., P.P., T.S., and Z.W.). The link for the survey was distributed to GI endoscopists in seven Asian countries via e-mail, and 154 endoscopists responded between October 2018 and January 2019.

\section{Selection of endoscopic images}

The endoscopic images were retrieved from the database of Asan Medical Center. An expert endoscopist (J.S.B.) reviewed the photos taken by high-definition colonoscopy (CF-H260AL/I or CF-HQ290AL/I; Olympus Medical, Tokyo, Japan) and selected high-quality images of 50 polyps (43 sessile or flat and seven pedunculated polyps), which clearly showed the following characteristics: size, gross appearance, and pit or vascular patterns of polyps. Of 50 sets of endoscopic images, 39 sets included both white light endoscopy images and narrow-band image. The other 11 sets comprised white light endoscopy images only.

\section{Statistical analysis}

Descriptive statistics were conducted to provide an overview of the polypectomy practice patterns. The chi-square and Fisher exact tests were used to evaluate the association of variables with the preference of CSP for diminutive and small polyps. Factors showing a p-value $<0.2$ were included to the logistic regression to identify the independent factors associated with specific techniques. A p-value $<0.05$ was considered statistically significant. SPSS version 21.0 for Windows software (IBM Corp., Armonk, NY, USA) was used.

\section{RESULTS}

\section{Demographic and professional background of the survey respondents}

Among 154 participants, 115 (74.7\%) completed the questionnaires. The rest completed the first part but omitted some questions in the second part of the questionnaire. The mean age of the respondents was $39.3 \pm 7.2$ years. The proportion of gastroenterology specialists and trainee endoscopists were $84.4 \%$ and $15.6 \%$, respectively. Other characteristics of the participants are described in Table 1.

\section{Preferred endoscopic resection techniques in the scenario-based questionnaire}

Table 2 summarizes the details of the preferred endoscopic resection method according to the given condition of polyps.

CFP was most preferred (78.6\%) for removing sessile or flat polyps $\leq 5 \mathrm{~mm}$ in all countries. CSP was the second most preferred technique (16.9\%) for sessile or flat polyps

Table 1. Demographic and Professional Background of the Survey Respondents

\begin{tabular}{|c|c|}
\hline Variable & Value \\
\hline Age, yr & $38(34-44)$ \\
\hline \multicolumn{2}{|l|}{ Age group, yr } \\
\hline$<35$ & 45 (29.2) \\
\hline $35-39$ & $41(26.6)$ \\
\hline $40-44$ & 35 (22.7) \\
\hline$\geq 45$ & $33(21.4)$ \\
\hline \multicolumn{2}{|l|}{ Sex } \\
\hline Male & 104 (67.5) \\
\hline Female & 50 (32.5) \\
\hline \multicolumn{2}{|l|}{ Country (ASR*; rank $^{\dagger}$ ) } \\
\hline Indonesia $(12.1 ; 4$ th $)$ & $16(10.4)$ \\
\hline Korea $(44.5 ; 2 n d)$ & $47(30.5)$ \\
\hline Malaysia (19.9; 2nd) & $15(9.7)$ \\
\hline Mongolia (6.2; 7th) & $24(15.6)$ \\
\hline Myanmar $(9.1 ; 6$ th $)$ & $7(4.5)$ \\
\hline Thailand $(13.3 ; 3 r d)$ & $40(26.0)$ \\
\hline Vietnam (13.4; 5th) & $5(3.2)$ \\
\hline \multicolumn{2}{|l|}{ Specialty } \\
\hline Staff gastroenterologist & 130 (84.4) \\
\hline Trainee gastroenterologist & $24(15.6)$ \\
\hline \multicolumn{2}{|l|}{ Type of practice } \\
\hline Primary clinic & 25 (16.2) \\
\hline Tertiary referral center & $129(83.8)$ \\
\hline \multicolumn{2}{|l|}{ Experience as an endoscopist, yr } \\
\hline$<1$ & $17(11.0)$ \\
\hline $1-3$ & $37(24.0)$ \\
\hline $4-10$ & 57 (37.0) \\
\hline$>10$ & $43(27.9)$ \\
\hline \multicolumn{2}{|l|}{ Volume of colonoscopy, case/yr } \\
\hline$<100$ & 19 (12.3) \\
\hline $100-499$ & 79 (51.3) \\
\hline $500-999$ & $31(20.1)$ \\
\hline$>1,000$ & 25 (16.2) \\
\hline
\end{tabular}

Data are presented as the median (interquartile range) or number (\%). *ASR stands for age-standardized rate (number of incident cases per 100,000 persons); ${ }^{\dagger}$ Rank means the rank of colorectal cancer incidence among overall malignancies in each country. 
Table 2. Preferred Endoscopic Resection Techniques for Nonpedunculated Polyps: Results of the Scenario-Based Survey

\begin{tabular}{|c|c|c|c|c|c|c|c|c|c|}
\hline Condition & Techniques & $\begin{array}{l}\text { Overall } \\
(n=154)\end{array}$ & $\begin{array}{l}\text { Indonesia } \\
\quad(n=16)\end{array}$ & $\begin{array}{l}\text { Korea } \\
(n=47)\end{array}$ & $\begin{array}{c}\text { Malaysia } \\
\text { (n=15) }\end{array}$ & $\begin{array}{c}\text { Mongolia } \\
\text { (n=24) }\end{array}$ & $\begin{array}{c}\text { Myanmar } \\
\text { (n=7) }\end{array}$ & $\begin{array}{l}\text { Thailand } \\
(\mathrm{n}=40)\end{array}$ & $\begin{array}{l}\text { Vietnam } \\
(n=5)\end{array}$ \\
\hline \multirow[t]{5}{*}{ Sessile or flat polyps $\leq 5 \mathrm{~mm}$} & CFP & $121(78.6)^{*}$ & $12(75.0)^{*}$ & $39(83.0)^{*}$ & $10(66.7)^{*}$ & 20 (83.3)* & $4(57.1)^{*}$ & 33 (82.5)* & $3(60.0)^{*}$ \\
\hline & CSP & $26(16.9)$ & $3(18.8)$ & $7(14.9)$ & 5 (33.3) & 0 & $3(42.9)$ & $6(15.0)$ & $2(40.0)$ \\
\hline & HSP & $3(1.9)$ & $1(6.3)$ & 0 & 0 & 2 (8.3) & 0 & 0 & 0 \\
\hline & EMR & $3(1.9)$ & 0 & $1(2.1)$ & 0 & 2 (8.3) & 0 & 0 & 0 \\
\hline & EPMR & $1(0.6)$ & 0 & 0 & 0 & 0 & 0 & $1(2.5)$ & 0 \\
\hline \multirow{5}{*}{$\begin{array}{l}\text { Sessile or flat polyps of } \\
\quad 6-9 \mathrm{~mm}\end{array}$} & CFP & $4(2.6)$ & $1(6.3)$ & 0 & 0 & $1(4.2)$ & 0 & $2(5.0)$ & 0 \\
\hline & CSP & 48 (31.2) & $6(37.5)$ & $13(27.7)$ & $10(66.7)^{*}$ & 0 & $2(28.6)$ & $16(40.0)$ & $1(20.0)$ \\
\hline & HSP & 59 (38.3)* & $9(56.3)^{*}$ & $4(8.5)$ & 5 (33.3) & 15 (62.5)* & 4 (57.1)* & $19(47.5)^{*}$ & $3(60.0) *$ \\
\hline & EMR & 42 (27.3) & 0 & $30(63.8)^{*}$ & 0 & 8 (33.3) & $1(14.3)$ & $2(5.0)$ & $1(20.0)$ \\
\hline & EPMR & $1(0.6)$ & 0 & 0 & 0 & 0 & 0 & $1(2.5)$ & 0 \\
\hline \multirow{7}{*}{$\begin{array}{l}\text { Benign-looking, sessile or flat } \\
\text { polyps of } 10-19 \mathrm{~mm}\end{array}$} & CFP & $1(0.6)$ & 0 & 0 & 0 & $1(4.2)$ & 0 & 0 & 0 \\
\hline & CSP & 6 (3.9) & $1(6.3)$ & $1(2.1)$ & 2 (13.3) & 0 & 0 & $2(5.0)$ & 0 \\
\hline & HSP & 52 (33.8) & $9(56.3)^{*}$ & 0 & 11 (73.3)* & $6(25.0)$ & 4 (57.1)* & $18(45.0)$ & $4(80.0) *$ \\
\hline & EMR & 88 (57.1)* & 6 (37.5) & 43 (91.5)* & 2 (13.3) & 13 (54.2)* & $3(42.9)$ & $20(50.0)^{*}$ & $1(20.0)$ \\
\hline & EPMR & 5 (3.2) & 0 & $2(4.3)$ & 0 & 3 (12.5) & 0 & 0 & 0 \\
\hline & ESD & $1(0.6)$ & 0 & 0 & 0 & $1(4.2)$ & 0 & 0 & 0 \\
\hline & Others ${ }^{\dagger}$ & $1(0.6)$ & 0 & $1(2.1)$ & 0 & 0 & 0 & 0 & 0 \\
\hline \multirow{7}{*}{$\begin{array}{l}\text { Benign-looking, sessile or flat } \\
\text { polyps } \geq 20 \mathrm{~mm}\end{array}$} & CFP & 0 & 0 & 0 & 0 & 0 & 0 & 0 & 0 \\
\hline & CSP & 0 & 0 & 0 & 0 & 0 & 0 & 0 & 0 \\
\hline & HSP & 22 (14.3) & $4(25.0)$ & $1(2.1)$ & $3(20.0)$ & $3(12.5)$ & $1(14.3)$ & $7(17.5)$ & $3(60.0) *$ \\
\hline & EMR & $64(41.6)^{*}$ & 5 (31.3) & 13 (27.7) & $19(66.7)^{*}$ & $11(45.8)^{*}$ & $5(71.4)^{*}$ & 19 (47.5)* & $1(20.0)$ \\
\hline & EPMR & 39 (25.3) & 6 (37.5)* & 12 (25.5) & 2 (13.3) & 8 (33.3) & $1(14.3)$ & 9 (22.5) & $1(20.0)$ \\
\hline & ESD & 23 (14.9) & $1(6.3)$ & $19(40.4)^{*}$ & 0 & 2 (8.3) & 0 & $1(2.5)$ & 0 \\
\hline & Others $^{\dagger}$ & 6 (3.9) & 0 & $2(4.3)$ & 0 & 0 & 0 & $4(10.0)$ & 0 \\
\hline \multirow{7}{*}{$\begin{array}{l}\text { Malignant-looking, sessile or } \\
\text { flat polyps of } 10-19 \mathrm{~mm}\end{array}$} & CFP & $1(0.6)$ & 0 & 0 & 0 & 0 & 0 & $1(2.5)$ & 0 \\
\hline & CSP & $1(0.6)$ & $1(6.3)$ & 0 & 0 & 0 & 0 & 0 & 0 \\
\hline & HSP & $11(7.1)$ & $3(18.8)$ & 0 & $2(13.3)$ & 0 & 0 & $6(15.0)$ & 0 \\
\hline & EMR & 73 (47.4)* & 10 (62.5)* & $20(42.6)$ & $9(60.0)^{*}$ & 8 (33.3) & $2(28.6)$ & $23(57.5)^{*}$ & $1(20.0)$ \\
\hline & EPMR & $11(7.1)$ & $1(6.3)$ & $1(2.1)$ & $1(6.7)$ & $5(20.8)$ & $1(14.3)$ & $2(5.0)$ & 0 \\
\hline & ESD & 48 (31.2) & $1(6.3)$ & $24(51.1)^{*}$ & $3(20.0)$ & $11(45.8)^{*}$ & 3 (42.9)* & $4(10.0)$ & $2(40.0) *$ \\
\hline & Others $^{\dagger}$ & $9(5.8)$ & 0 & $2(4.3)$ & 0 & 0 & $1(14.3)$ & $4(10.0)$ & $2(40.0)$ \\
\hline \multirow{7}{*}{$\begin{array}{l}\text { Malignant-looking, sessile or } \\
\text { flat polyps } \geq 20 \mathrm{~mm}\end{array}$} & CFP & $1(0.6)$ & 0 & $1(2.1)$ & 0 & 0 & 0 & 0 & 0 \\
\hline & CSP & 0 & 0 & 0 & 0 & 0 & 0 & 0 & 0 \\
\hline & HSP & $7(4.5)$ & $1(6.3)$ & $1(2.1)$ & $1(6.7)$ & 0 & 0 & $4(10.0)$ & 0 \\
\hline & EMR & $17(11.0)$ & $2(12.5)$ & $1(2.1)$ & 2 (13.3) & $5(20.8)$ & 0 & $7(17.5)$ & 0 \\
\hline & EPMR & 23 (14.9) & $4(25.0)$ & 0 & $3(20.0)$ & $3(12.5)$ & 3 (42.9)* & $9(22.5)$ & $1(20.0)$ \\
\hline & ESD & $87(56.5)^{*}$ & $7(43.8)^{*}$ & $44(93.6)^{*}$ & $7(46.7)^{*}$ & $16(66.7)^{*}$ & $2(28.6)$ & $10(25.0)^{*}$ & $1(20.0)$ \\
\hline & Others $^{\dagger}$ & 19 (12.3) & 2 (12.5) & 0 & 2 (13.3) & 0 & $2(28.6)$ & $10(25.0)^{*}$ & $3(60.0) *$ \\
\hline \multirow{4}{*}{$\begin{array}{l}\text { Real-time histologic diagnosis } \\
\text { before selecting polypec- } \\
\text { tomy method }\end{array}$} & WLE only & $12(7.8)$ & $1(6.3)$ & $6(12.8)$ & $1(6.7)$ & $1(4.2)$ & 0 & $2(5.0)$ & $1(20.0)$ \\
\hline & DCE after WLE & $4(2.6)$ & 0 & 0 & 0 & 0 & 0 & 0 & 0 \\
\hline & IEE after WLE & $112(72.7)^{*}$ & 14 (87.5)* & $34(72.3)^{*}$ & $13(86.7)^{*}$ & $7(29.2)$ & $3(42.9)$ & 38 (95.0)* & $3(60.0) *$ \\
\hline & DCE and IEE & $26(16.9)$ & $1(6.3)$ & $7(14.9)$ & $1(6.7)$ & $12(50.0)^{*}$ & $4(57.1)^{*}$ & 0 & $1(20.0)$ \\
\hline
\end{tabular}

Data are presented as number (\%).

CFP, cold forceps polypectomy; CSP, cold snare polypectomy; HSP, hot snare polypectomy; EMR, endoscopic mucosal resection; EPMR, endoscopic piecemeal mucosal resection; ESD, endoscopic submucosal dissection; WLE, white light endoscopy; DCE, dye chromoendoscopy; IEE, image-enhanced endoscopy.

*The most preferred method for each condition; ${ }^{\dagger}$ Others indicates referring the case to specialist endoscopists or surgeons.

$\leq 5 \mathrm{~mm}$ in all countries except Mongolia. For sessile or flat polyps of 6-9 mm, CSP and EMR were the most preferred techniques in Malaysia and Korea, respectively. However, HSP was the most common technique for sessile or flat polyps of $6-9 \mathrm{~mm}$ in size in the other five countries. Factors associated with the preference for CSP for nonpedunculated polyps 6-9 $\mathrm{mm}$ in size were trainee endoscopists, endoscopists of tertiary referral centers, and endoscopists in countries where the incidence of CRC was in the top three among all malignancies (Table 3 ).

For benign-looking sessile or flat polyps of 10-19 mm in size, EMR and HSP were the most and second most preferred methods, respectively, among the overall respondents, but the endoscopists from Indonesia, Malaysia, 
Table 3. Factors Associated with Preference to CSP for Diminutive and Small Polyps

\begin{tabular}{|c|c|c|c|c|c|c|c|c|}
\hline \multirow{3}{*}{ Characteristics of the respondents } & \multirow{2}{*}{\multicolumn{3}{|c|}{$\frac{\text { Diminutive }(\leq 5 \mathrm{~mm}) \text { polyps }}{\text { Univariate analysis }}$}} & \multicolumn{5}{|c|}{ Small (6-9 mm) polyps } \\
\hline & & & & \multicolumn{3}{|c|}{ Univariate analysis } & \multicolumn{2}{|c|}{ Multivariate analysis } \\
\hline & CSP & Others & $\mathrm{p}$-value & CSP & Others & p-value & OR $(95 \% \mathrm{Cl})$ & $\mathrm{p}$-value \\
\hline Age group, yr & & & 0.171 & & & 0.400 & & \\
\hline$<35$ & 4 & 41 & & 12 & 33 & & & \\
\hline $35-39$ & 11 & 30 & & 17 & 24 & & & \\
\hline $40-44$ & 6 & 29 & & 9 & 26 & & & \\
\hline$\geq 45$ & 5 & 28 & & 10 & 23 & & & \\
\hline Sex & & & 0.508 & & & 0.183 & & \\
\hline Male & 19 & 85 & & 36 & 68 & & & \\
\hline Female & 7 & 43 & & 12 & 38 & & & \\
\hline Specialty & & & 0.560 & & & 0.002 & & \\
\hline Staff GI endoscopist & 21 & 109 & & 34 & 96 & & 1 (reference) & \\
\hline Trainee GI endoscopist & 5 & 19 & & 14 & 10 & & $4.009(1.519-10.576)$ & 0.005 \\
\hline Type of practice & & & 0.770 & & & 0.024 & & \\
\hline Primary clinic & 5 & 20 & & 3 & 22 & & 1 (reference) & \\
\hline Referral center & 21 & 108 & & 45 & 84 & & $4.783(1.302-17.568)$ & 0.018 \\
\hline Experience as an endoscopist, yr & & & 0.615 & & & 0.129 & & \\
\hline$\leq 3$ & 8 & 46 & & 21 & 33 & & & \\
\hline$>3$ & 18 & 82 & & 27 & 73 & & & \\
\hline Volume of colonoscopy per year, case & & & 0.490 & & & 0.375 & & \\
\hline$\leq 499$ & 15 & 83 & & 33 & 65 & & & \\
\hline$\geq 500$ & 11 & 45 & & 15 & 41 & & & \\
\hline Annual incidence of CRC in their countries & & & 0.501 & & & 0.192 & & \\
\hline ASR $<15^{*}$ & 14 & 78 & & 25 & 67 & & & \\
\hline ASR $\geq 15^{*}$ & 12 & 50 & & 23 & 39 & & & \\
\hline Rank of CRC incidence among all malignancies & & & 0.723 & & & 0.008 & & \\
\hline$\leq 4$ th in each country & 8 & 44 & & 9 & 43 & & 1 (reference) & \\
\hline$\geq 3 r d$ in each country & 18 & 84 & & 39 & 63 & & $3.098(1.321-7.270)$ & 0.009 \\
\hline
\end{tabular}

CSP, cold snare polypectomy; OR, odds ratio; $\mathrm{Cl}$, confidence interval; $\mathrm{Gl}$, gastrointestinal; CRC, colorectal cancer.

*ASR stands for age-standardized rate (number of incident cases per 100,000 persons).

Myanmar, and Vietnam preferred HSP over EMR. EMR and EPMR were the most and second most preferred resection methods, respectively, for benign-looking sessile or flat polyps $\geq 20 \mathrm{~mm}$ by the overall respondents, but ESD was the most preferred technique by Korean endoscopists.

For malignant-looking sessile or flat polyps $10-19 \mathrm{~mm}$ in size, EMR was the most preferred method in Indonesia, Malaysia, and Thailand. Meanwhile, ESD was the most preferred method in Korea, Mongolia, and Vietnam. For malignant-looking, sessile or flat polyps $\geq 20 \mathrm{~mm}$, ESD was the most preferred technique in all countries except Myanmar and Vietnam.

HSP was the most preferred technique for pedunculated polyps by the overall respondents, but EMR was the most preferred technique in Korea (Table 4). Prophylactic hemostasis would be performed by $65.4 \%$ of the overall respondents before removing the pedunculated polyps with head size $<20 \mathrm{~mm}$ or stalk width $<10 \mathrm{~mm}$, and $89.6 \%$ of them would perform prophylactic hemostasis before resection of pedunculated polyps with head size $\geq 20 \mathrm{~mm}$ or stalk width $\geq 10 \mathrm{~mm}$.

\section{Preferred endoscopic resection techniques in the image-based questionnaire}

Of 7,700 sets of questions for 154 participants (50 sets per participant), 6,112 (79.4\%) were answered. For benignlooking sessile or flat polyps $\leq 5 \mathrm{~mm}$, CFP and CSP were the most and second most preferred techniques, respectively, but EMR was the most preferred method if submucosal invasion was suspected. EMR was the most preferred technique for sessile or flat polyps 6-9 $\mathrm{mm}$ in size regardless of suspected submucosal invasion. For sessile or flat polyps $10-19 \mathrm{~mm}$ in size, EMR was most preferred if no submucosal invasion was suspected, but ESD was most preferred if submucosal invasion was suspected. For sessile or flat polyps $>20 \mathrm{~mm}$ in size, ESD was preferred over the other methods regardless of submucosal invasion. For pedunculated polyps with head size of 10-19 mm, HSP was most preferred if they looked benign, but EMR was preferred over the other techniques if submucosal invasion was suspected. Details are described in Table 5. 
Table 4. Preferred Endoscopic Resection Techniques for Pedunculated Polyps: Results of the Scenario-Based Survey

\begin{tabular}{|c|c|c|c|c|c|c|c|c|c|}
\hline Condition & Techniques & $\begin{array}{l}\text { Overall } \\
\text { (n=154) }\end{array}$ & $\begin{array}{l}\text { Indonesia } \\
\quad(n=16)\end{array}$ & $\begin{array}{l}\text { Korea } \\
(n=47)\end{array}$ & $\begin{array}{c}\text { Malaysia } \\
\text { (n=15) }\end{array}$ & $\begin{array}{l}\text { Mongolia } \\
(n=24)\end{array}$ & $\begin{array}{c}\text { Myanmar } \\
(n=7)\end{array}$ & $\begin{array}{l}\text { Thailand } \\
(n=40)\end{array}$ & $\begin{array}{c}\text { Vietnam } \\
(n=5)\end{array}$ \\
\hline \multirow{4}{*}{$\begin{array}{l}\text { Pedunculated polyps with } \\
\text { head size }<20 \mathrm{~mm} \text { and } \\
\text { stalk width }<10 \mathrm{~mm}\end{array}$} & CSP & $11(7.1)$ & $1(6.3)$ & 0 & $1(6.7)$ & $7(29.2)$ & 0 & 2 (5.0) & 0 \\
\hline & HSP & $100(64.9)^{*}$ & $13(81.3)^{*}$ & 15 (31.9] & $13(86.7) *$ & 13 (54.2)* & 6 (85.7)* & 35 (87.5)* & $5(100)^{*}$ \\
\hline & EMR & $40(26.0)$ & $2(12.5)$ & $32(68.1)^{*}$ & $1(6.7)$ & $2(8.3)$ & $1(14.3)$ & $2(5.0)$ & 0 \\
\hline & ESD & $3(1.9)$ & 0 & 0 & 0 & 2 (8.3) & 0 & $1(2.5)$ & 0 \\
\hline \multirow[t]{3}{*}{ Prophylactic hemostasis } & Clipping & 91 (59.1)* & $12(75.0)^{*}$ & 15 (31.9) & 5 (33.3) & 21 (87.5)* & $5(71.4)^{*}$ & $30(75.0)^{*}$ & $3(60.0)^{*}$ \\
\hline & Detachable s & $10(6.5)$ & $1(6.3)$ & $2(4.3)$ & $1(6.7)$ & $3(12.5)$ & $1(14.3)$ & $1(2.5)$ & $1(20.0)$ \\
\hline & None & 53 (34.4) & $3(18.8)$ & $30(63.8)^{*}$ & $9(60.0)^{*}$ & 0 & $1(14.3)$ & $9(22.5)$ & $1(20.0)$ \\
\hline \multirow{5}{*}{$\begin{array}{l}\text { Pedunculated polyps with } \\
\text { head size } \geq 20 \mathrm{~mm} \text { or } \\
\text { stalk width } \geq 10 \mathrm{~mm}\end{array}$} & CSP & $1(0.6)$ & 0 & 0 & 0 & 0 & $1(14.3)$ & 0 & 0 \\
\hline & HSP & $90(58.4)^{*}$ & $12(75.0)^{*}$ & 12 (25.5) & 13 (86.7)* & $11(45.8)^{*}$ & $6(85.7)^{*}$ & $32(80.0)^{*}$ & $4(80.0)^{*}$ \\
\hline & EMR & $58(37.7)$ & $4(25.0)$ & $34(72.3)^{*}$ & $2(13.3)$ & $11(45.8)^{*}$ & 0 & $6(15.0)$ & $1(20.0)$ \\
\hline & ESD & $3(1.9)$ & 0 & $1(2.1)$ & 0 & $2(8.3)$ & 0 & 0 & 0 \\
\hline & Others $^{\dagger}$ & $2(1.3)$ & 0 & 0 & 0 & 0 & 0 & $2(5.0)$ & 0 \\
\hline \multirow[t]{3}{*}{ Prophylactic hemostasis } & Clipping & $87(56.5)^{*}$ & $7(43.8)^{*}$ & $20(42.6)^{*}$ & $7(46.7)^{*}$ & 20 (83.3)* & $4(57.1)^{*}$ & $28(70.0)^{*}$ & $1(20.0)$ \\
\hline & Detachabl & $51(33.1)$ & $7(43.8)^{*}$ & $19(40.4)$ & $4(26.7)$ & $4(16.7)$ & $3(42.9)$ & $11(27.5)$ & $3(60.0)^{*}$ \\
\hline & None & $16(10.4)$ & $2(12.5)$ & $8(17.0)$ & $4(26.7)$ & 0 & 0 & $1(2.5)$ & $1(20.0)$ \\
\hline
\end{tabular}

Values are presented as number (\%).

CSP, cold snare polypectomy; HSP, hot snare polypectomy; EMR, endoscopic mucosal resection; ESD, endoscopic submucosal dissection.

*The most preferred method for each condition; ${ }^{+}$Others indicates referring the case to specialist endoscopists.

\section{DISCUSSION}

In the current survey for preferred polypectomy techniques of Asian endoscopists, the most preferred techniques for diminutive $(\leq 5 \mathrm{~mm})$, small $(6-9 \mathrm{~mm})$, and benign-looking intermediate (10-19 $\mathrm{mm}$ ) nonpedunculated polyps were CFP, HSP, and EMR, respectively, in both the scenario- and image-based questionnaires. For benignlooking large $(\geq 20 \mathrm{~mm})$ nonpedunculated polyps, EMR and ESD were the most common choices in the scenarioand image-based surveys, respectively. In case of malignant nonpedunculated polyps, EMR and ESD were preferred for intermediate-sized and large lesions, respectively, according to the scenario-based survey. However, ESD was preferred in both intermediate-sized and large malignant nonpedunculated polyps when endoscopic images of lesions were provided.

Our survey showed that CFP was the most preferred resection method of the overall respondents for diminutive sessile or flat polyps. For small sessile or flat polyps, HSP was the most preferred technique in Indonesia, Mongolia, Myanmar, Thailand, and Vietnam, and EMR was the most preferred technique in Korea. Only Malaysian endoscopists preferred CSP over the other methods for removing small sessile or flat polyps. However, both ESGE and U.S. Multi-Society Task Force guidelines recommend CSP as the procedure of choice for diminutive and small sessile or flat polyps. ${ }^{2,7}$ Currently available evidence supports these recommendations. The incomplete resection rate of CFP for polyps $\leq 5 \mathrm{~mm}$ ranged from $9 \%$ to $61 \%,{ }^{9-11}$ and CSP is estimated to reduce the incomplete resection rate of CFP by $79 \%$ (relative risk [RR], $0.21 ; 95 \%$ confidence interval [CI], 0.14 to 0.67 ) based on a recent meta-analysis. ${ }^{12}$ According to a randomized controlled trial comparing CSP with HSP for polyps $4-9 \mathrm{~mm}$ in size, ${ }^{13}$ both procedures showed excellent complete resection rate $(98.2 \%$ for CSP vs 97.4\% for HSP), but postpolypectomy bleeding occurred only in the HSP group (0.5\%). Another meta-analysis, including eight studies comparing CSP with HSP for polyps mainly $5-7 \mathrm{~mm}$ in size, reported that the two procedures showed similar complete resection (RR, 1.02; 95\% CI, 0.98 to 1.07 ) and tissue retrieval rates (RR, $1.00 ; 95 \% \mathrm{CI}, 1.00$ to 1.01 ) ${ }^{14}$ However, the total procedure time (mean difference, 7.13 minutes; 95\% CI, 5.32 to 8.94 ) and specific polypectomy time (mean difference, 30.92 seconds; $95 \%$ CI, 9.15 to 52.68) were significantly longer in HSP than in $\mathrm{CSP}^{14}$ In the same meta-analysis, HSP showed a trend toward higher delayed bleeding rate than CSP (RR, 7.53; 95\% CI, 0.94 to 60.24$).{ }^{14}$ Despite such advantages of CSP over CFP or HSP, remarkably, our survey reveals that CSP remains a procedure rarely used for removing diminutive or small polyps in Asian countries. As in our study, CFP was the most preferred treatment for diminutive polyps in a Japanese survey of nine participants published in $2014 .^{5}$ Meanwhile, the outcomes of an Australian survey including 244 respondents were partly different from ours. ${ }^{6}$ That is, $67.6 \%$ of the Australian endoscopists preferred CSP over the others for polyps $<3 \mathrm{~mm}$ and $49.2 \%$ for polyps $4-6$ $\mathrm{mm}$ in size. However, for removing polyps $7-9 \mathrm{~mm}$ in size, EMR was the most preferred (60.7\%) technique and only $7.4 \%$ preferred CSP in that survey. ${ }^{6}$

According to the multivariate analysis of the scenario- 
Table 5. Preferred Endoscopic Resection Techniques According to the Provided Endoscopic Images of the Polyps*

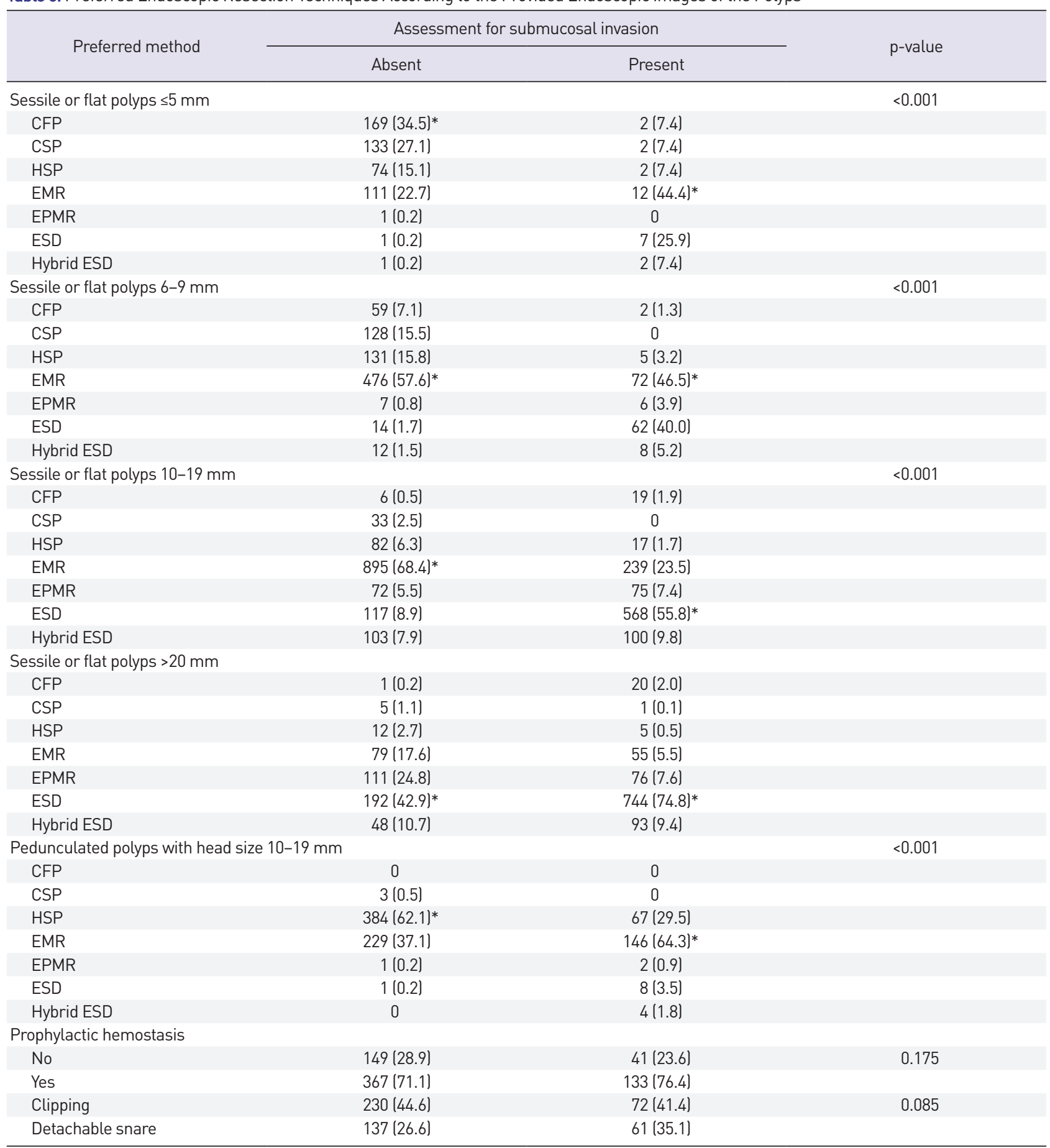

Data are presented as number (\%). Unanswered questions (1,588/7,700; 20.6\%) were not included.

CFP, cold forceps polypectomy; CSP, cold snare polypectomy; HSP, hot snare polypectomy; EMR, endoscopic mucosal resection; EPMR, endoscopic piecemeal mucosal resection; ESD, endoscopic submucosal dissection.

*The most preferred method for each condition.

based survey data, trainee endoscopists, endoscopists working in referral centers, and endoscopists in countries where CRC was ranked within the top three common malignancies were independently associated with preference for CSP for removing small polyps. Endoscopists in referral centers or in CRC-prevalent countries may have a greater awareness of the advantages of CSP over other techniques for removing diminutive or small polyps than those in the primary clinics or in countries with relatively low CRC incidence. The negative association of staff endoscopists with 
CSP for small polyps is an interesting finding and suggests that educational efforts are necessary to change the clinical practice of endoscopists who still follow outdated procedures. However, our survey cannot reveal the reasons for the lower preference for CSP as a treatment of diminutive and small polyps because the questionnaires did not ask the reasons of the respondents' decisions. In addition to the unawareness of the advantages of CSP for the diminutive and small polyps, the availability of dedicated snares for CSP might have affected the responses. According to a Korean survey for polypectomy methods published in $2011,{ }^{4} 205$ (81.3\%) of 252 respondents preferred CFP and only four (1.6\%) preferred CSP for diminutive polyps. CFP was still the most preferred technique for diminutive polyps in Korean endoscopists in the current survey conducted in 2018 to 2019. However, interestingly, 14.9\% of Korean respondents chose CSP for resection of diminutive polyps, which is higher compared to the proportion (1.6\%) in the previous Korean study in $2011 .{ }^{4}$ Similarly, regarding polyps $6-9 \mathrm{~mm}$ in size, $27.7 \%$ of the Korean endoscopists in the current survey preferred CSP compared to none of the respondents in the previous Korean survey. ${ }^{4}$ These changes in the preference of Korean endoscopists may have resulted from the continuous education and accumulation of evidence supporting CSP rather than CFP and HSP. The recent introduction of dedicated snares for CSP in the Korean market may have contributed to the current increase in CSP practice in Korea as well.

The reported risk of CRC in diminutive and small polyps ranges from $0 \%$ to $0.03 \%$ and from $0 \%$ to $0.2 \%$, respectively; ${ }^{15,16}$ thus, recent guidelines do not consider the resection methods for these extremely rare conditions. ${ }^{2,7}$ Nonetheless, according to the responses in the endoscopic image-based questionnaire, EMR was the most preferred technique when submucosal invasion was suspected in the provided images of diminutive or small polyps. Considering the lack of submucosal tissue in the CSP specimens, ${ }^{17,18}$ choosing EMR as a resection method for potentially malignant diminutive or small polyps seems reasonable, although very few evidence is available at this moment.

In the current survey, EMR was the most preferred technique for benign sessile or flat polyps $10-19 \mathrm{~mm}$ in size, as recommended by ESGE. ${ }^{2}$ However, endoscopists in Indonesia, Malaysia, Myanmar, and Vietnam preferred HSP without submucosal injection for benign-looking sessile or flat polyps 10-19 $\mathrm{mm}$ in size, unlike the ESGE recommendation. According to a prospective study of patients scheduled to undergo CRC surgery, HSP without submucosal solution damaged deep submucosa in $60 \%$ and muscularis propria in $20 \% .{ }^{19}$ Therefore, submucosal injection followed by HSP (i.e., EMR) should be performed for sessile polyps $10-19 \mathrm{~mm}$ in size to reduce the risk of deep thermal injury, ${ }^{2}$ although studies comparing the risk of adverse events between HSP and EMR are not available in polyps $10-19 \mathrm{~mm}$ in size. For malignant-looking polyps 10-19 mm size, EMR and ESD were the most and second most preferred methods in the current survey, which were consistent with current guidelines. ${ }^{2}$ The preference for EMR and ESD for this type of polyp was similar between the scenario- and image-based questionnaires.

For benign-looking nonpedunculated polyps $\geq 20 \mathrm{~mm}$ in size, EMR and EPMR were preferred by the overall respondents. However, the proportion of ESD was highest in this type of lesions among the Korean endoscopists, reflecting the regulation and medical reimbursement system for colorectal ESD in Korea. ${ }^{20,21}$ ESD was the most preferred resection method for malignant-looking nonpedunculated polyps $\geq 20 \mathrm{~mm}$ by the overall respondents. However, when shown photos of nonpedunculated polyps $\geq 20 \mathrm{~mm}$, most respondents selected ESD regardless of the assessment for submucosal invasion. This finding was attributed to the higher proportion of nonpedunculated polyps $\geq 30 \mathrm{~mm}$ in size in the provided photos of polyps $\geq 20 \mathrm{~mm}$. In addition, the potential interobserver disagreement on the morphologic classification of the given endoscopic images ${ }^{22}$ might have resulted in the discrepancies between the scenarioand image-based questionnaires, although interobserver agreement for morphology was not evaluated in the current study.

HSP was preferred for pedunculated polyps either $10-19$ or $\geq 20 \mathrm{~mm}$ in size in all countries, except Korea. Korean endoscopists preferred EMR to other methods for pedunculated polyps $\geq 10 \mathrm{~mm}$ in size, but the reason could not be determined in this survey. According to the survey responses, $65.6 \%$ and $89.6 \%$ of respondents decided to perform prophylactic hemostasis for pedunculated polyps with head $<20 \mathrm{~mm}$ or stalks $<10 \mathrm{~mm}$ and for those with head $\geq 20 \mathrm{~mm}$ or with stalk $\geq 10 \mathrm{~mm}$, respectively.

This survey-based study has several limitations. First, as an innate limitation of surveys, the responses of the study participants cannot accurately reflect their real-life clinical practice. Currently, little is known about adherence to ESGE guidelines, and additional studies should be followed to determine the real adherence to the guidelines. Second, despite the multivariate analysis for the factors associated with the preference for CSP, this survey cannot reveal the specific reasons for the lesser preference for CSP as a treatment of diminutive and small polyps because the reasons for the respondents' decisions were not queried. Third, questions did not include the availability of specific devices or procedures, which could significantly affect the endoscopist's practice pattern in each country. Fourth, the num- 
bers of study participants are widely variable among countries. The Korean and Thai endoscopists occupied 56.5\% of all respondents and endoscopists from the other five countries occupied the remaining. For example, a prejudiced selection of EMR for removing benign-looking sessile or flat polyps $10-19 \mathrm{~mm}$ in size by Korean endoscopists may affect the preference of overall participants, although HSP was the most preferred technique in Indonesia, Malaysia, Myanmar, and Vietnam. The imbalance by outliers of the subgroup has the potential to distort the estimate of the parameter of interest and thus compromise the generalizability of the findings. Therefore, the procedures preferred by the "overall" respondents in the current study should be interpreted with caution. Finally, the lack of consideration for each country's medical reimbursement policies made it impossible to interpret the responses, especially if such responses are far from the current guidelines. The disparity between the current guidelines and the endoscopists' responses would reflect the diversity in national health care policy and medical reimbursement system of each country. At this viewpoint, the application of the guidelines adjusted to individual countries may be acceptable. Nonetheless, our survey provides insights about the variation of polypectomy practice patterns among countries of Asia and raises the necessity of continuous education and polypectomy guidelines reflecting evidence and medical situations of Asian countries.

In conclusion, polypectomy practice patterns of Asian endoscopists vary among countries. The reason for preference of CFP or HSP rather than CSP for diminutive or small polyps should be investigated, and subsequently, region-specific polypectomy guidelines should be developed and propagated for effective and safe prevention of CRC in Asia.

\section{CONFLICTS OF INTEREST}

No potential conflict of interest relevant to this article was reported.

\section{AUTHOR CONTRIBUTIONS}

Study concept and design: J.S.B. Data acquisition: B.L., Q.T.T., A.F., P.P., T.S., Z.W., J.S.B. Data analysis and interpretation: D.H.Y., B.L. Statistical analysis: D.H.Y., B.L. Drafting of the manuscript: D.H.Y., B.L. Critical revision of the manuscript for important intellectual content: Q.T.T., A.F., P.P., T.S., Z.W., J.S.B. Study supervision: J.S.B.

\section{ORCID}

Dong-Hoon Yang https://orcid.org/0000-0001-7756-2704

Bayasgalan Luvsandagva

https://orcid.org/0000-0002-7899-4100

Quang Trung Tran https://orcid.org/0000-0001-8347-1614

Achmad Fauzi https://orcid.org/0000-0001-5189-8840

Panida Piyachaturawat

https://orcid.org/0000-0003-0972-5895

Thida Soe https://orcid.org/0000-0002-7928-7969

Zhiqin Wong https://orcid.org/0000-0002-9060-8348

Jeong-Sik Byeon https://orcid.org/0000-0002-9793-6379

\section{REFERENCES}

1. Zauber AG, Winawer SJ, O'Brien MJ, et al. Colonoscopic polypectomy and long-term prevention of colorectal-cancer deaths. N Engl J Med 2012;366:687-696.

2. Ferlitsch M, Moss A, Hassan C, et al. Colorectal polypectomy and endoscopic mucosal resection (EMR): European Society of Gastrointestinal Endoscopy (ESGE) Clinical Guideline. Endoscopy 2017;49:270-297.

3. Singh N, Harrison M, Rex DK. A survey of colonoscopic polypectomy practices among clinical gastroenterologists. Gastrointest Endosc 2004;60:414-418.

4. Shin SJ, Lee SH, Park DI, et al. A Korean national survey for treatment modality in colon polypectomy. Intest Res 2011;9:196-205.

5. Matsuda T, Kawano H, Hisabe T, et al. Current status and future perspectives of endoscopic diagnosis and treatment of diminutive colorectal polyps. Dig Endosc 2014;26 Suppl 2:104-108.

6. Chandran S, Parker F, Vaughan R, Efthymiou M. The current practice standard for colonoscopy in Australia. Gastrointest Endosc 2014;79:473-479.

7. Kaltenbach T, Anderson JC, Burke CA, et al. Endoscopic removal of colorectal lesions-recommendations by the US Multi-Society Task Force on colorectal cancer. Gastroenterology 2020;158:1095-1129.

8. Ferlay J, Ervik M, Lam F, et al. Global Cancer Observatory: Cancer Today [Internet]. Lyon: International Agency for Research on Cancer; c2018 [cited 2019 Dec 20]. Available from: https://gco.iarc.fr/today.

9. Efthymiou M, Taylor AC, Desmond PV, Allen PB, Chen RY. Biopsy forceps is inadequate for the resection of diminutive polyps. Endoscopy 2011;43:312-316.

10. Draganov PV, Chang MN, Alkhasawneh A, et al. Randomized, controlled trial of standard, large-capacity versus jumbo biopsy forceps for polypectomy of small, sessile, colorectal polyps. Gastrointest Endosc 2012;75:118-126. 
11. Jung YS, Park JH, Kim HJ, et al. Complete biopsy resection of diminutive polyps. Endoscopy 2013;45:1024-1029.

12. Raad D, Tripathi P, Cooper G, Falck-Ytter Y. Role of the cold biopsy technique in diminutive and small colonic polyp removal: a systematic review and meta-analysis. Gastrointest Endosc 2016;83:508-515.

13. Kawamura T, Takeuchi Y, Asai S, et al. A comparison of the resection rate for cold and hot snare polypectomy for 4-9 mm colorectal polyps: a multicentre randomized controlled trial (CRESCENT study). Gut 2018;67:1950-1957.

14. Shinozaki S, Kobayashi Y, Hayashi Y, Sakamoto H, Lefor AK, Yamamoto H. Efficacy and safety of cold versus hot snare polypectomy for resecting small colorectal polyps: systematic review and meta-analysis. Dig Endosc 2018;30:592-599.

15. Ponugoti PL, Cummings OW, Rex DK. Risk of cancer in small and diminutive colorectal polyps. Dig Liver Dis 2017;49:34-37.

16. Lieberman D, Moravec M, Holub J, Michaels L, Eisen G. Polyp size and advanced histology in patients undergoing colonoscopy screening: implications for CT colonography.
Gastroenterology 2008;135:1100-1105.

17. Suzuki S, Gotoda T, Kusano C, et al. Width and depth of resection for small colorectal polyps: hot versus cold snare polypectomy. Gastrointest Endosc 2018;87:1095-1103.

18. Yoshida N, Naito Y, Murakami T, et al. A diminutive T1 cancer $4 \mathrm{~mm}$ in size resected by cold snare polypectomy. Case Rep Gastroenterol 2018;12:27-31.

19. Takayanagi D, Nemoto D, Isohata N, et al. Histological comparison of cold versus hot snare resections of the colorectal mucosa. Dis Colon Rectum 2018;61:964-970.

20. Kim TJ, Kim ER, Hong SN, Kim YH, Chang DK. Current practices in endoscopic submucosal dissection for colorectal neoplasms: a survey of indications among Korean endoscopists. Intest Res 2017;15:228-235.

21. Chang DK. Current status of colorectal endoscopic submucosal dissection in Korea. Clin Endosc 2012;45:288-289.

22. van Doorn SC, Hazewinkel Y, East JE, et al. Polyp morphology: an interobserver evaluation for the Paris classification among international experts. Am J Gastroenterol 2015;110:180-187. 